\title{
The Prevalence of Celiac Disease-Specific Auto-Antibodies in Type 1 Diabetes in a Moroccan Population
}

\author{
Ider Oujamaa $\mathbb{D}^{1},{ }^{1}$ Majda Sebbani, ${ }^{2}$ Lahcen Elmoumou, ${ }^{1}$ Aïcha Bourrahouate, ${ }^{3}$ \\ Rabiy El Qadiry (D, , ${ }^{3}$ Soufian El Moussaoui, ${ }^{3}$ Imane Ait Sab, ${ }^{3}$ Mohamed Sbihi, ${ }^{3}$ \\ Laila Ennazk (D), ${ }^{4}$ Ghizlane El Mghari-Tabib, ${ }^{4}$ Nawal El Ansari, ${ }^{4}$ Hicham Baizri, ${ }^{5}$ \\ Mohamed Amine, ${ }^{2}$ and Brahim Admou $\mathbb{D i D}^{1,6}$ \\ ${ }^{1}$ Laboratory of Immunology, University Hospital of Marrakech, Marrakech, Morocco \\ ${ }^{2}$ Department of Public Health and Epidemiology, PCIM Research Laboratory, Cadi Ayyad University, \\ Marrakech, Morocco \\ ${ }^{3}$ Department of Pediatrics, University Hospital of Marrakech, Marrakech, Morocco \\ ${ }^{4}$ Department of Endocrinology, University Hospital of Marrakech, Marrakech, Morocco \\ ${ }^{5}$ Department of Endocrinology, Ibn Sina Military Hospital, Marrakech, Morocco \\ ${ }^{6}$ ERCIM Research Team, Faculty of Medecine and Pharmacy, Cadi Ayyad University, Marrakech, Morocco \\ Correspondence should be addressed to Brahim Admou; br.admou@uca.ac.ma
}

Received 28 February 2019; Revised 20 June 2019; Accepted 13 August 2019; Published 19 September 2019

Academic Editor: Basilio Pintaudi

Copyright (C) 2019 Ider Oujamaa et al. This is an open access article distributed under the Creative Commons Attribution License, which permits unrestricted use, distribution, and reproduction in any medium, provided the original work is properly cited.

\begin{abstract}
Objective. We aimed to determine the prevalence of specific auto-antibodies to celiac disease (CD) in Moroccan type 1 diabetic (T1D) patients and compare the clinical and biological characteristics of seropositive and seronegative cases. Patients and Methods. A cross-sectional study was carried out on 276 T1D patients including 109 adults and 167 pediatric cases. The screening for $\mathrm{CD}$ was performed by an Elisa IgA anti-tissue transglutaminase antibody (tTGA) testing, combined with IgA quantification by nephelometry. Positive-IgA-tTGA cases were secondly tested for anti-endomysial antibodies (EMA) using an immunofluorescence technique, and the IgA deficiency cases were screened for IgG-tTGA. Patients with low positive tTGA titers underwent HLA-DQ2/DQ8 typing. Sociodemographic and clinical data of the patients were collected using a hetero-administered questionnaire. The comparison of clinical and biological data between seropositive and seronegative diabetics was done using independent $T$, Mann-Whitney $U$, chi-squared, and Fisher tests, which were considered significant if $p$ value $<0.05$. Results. The prevalence of CD-specific auto-antibodies was estimated to be $9.1 \%(\mathrm{IC}=95 \%)$, with 25 positive cases in tTGA and EMA testing. Eight cases displayed low titers of IgA-tTGA, among which 4 were positive for HLA-DQ2, 1 for HLA-DQ8, and 1 for both DQ2 and DQ8. The other 2 cases had a biopsy-proven CD. Compared to seronegative patients, seropositive cases had a higher percentage of associated autoimmune disorders ( $16 \%$ vs. $2.4 \%, p=0.008)$, with a significant lower height Z-scores (median: -0.90 (-3.93 to 0.95$)$ vs. -0.51 ( -4.54 to 2.18 ), $p=0.029$ ) and a higher HbAlc level (median: $11.30 \%$ (7.31 to 16.00$)$ vs. 9.30\% (4.40 to17.31), $p=0.022$ ). Conclusion. The current study gave evidence of a high prevalence of CD specific auto-antibodies in T1D population. The co-existence of these two conditions was associated with a poor glycemic control, a lower height, and other autoimmune diseases. These findings may suggest the necessity of a systematic screening of CD in T1D patients.
\end{abstract}

\section{Introduction}

The association between celiac disease (CD) and type 1 diabetes (T1D) was first reported during the sixties [1]. This association has become nowadays well-known and more common with the development of sensitive and specific related serological tests.
The prevalence of $\mathrm{CD}$ in T1D patients is reported to be 5 to 7 times greater than in the general population [2]. In a meta-analysis gathering 27 studies with a total of $26,605 \mathrm{~T} 1 \mathrm{D}$ patients, Elfström found that the overall prevalence of biopsy-proven CD is almost 6\% [3]. Till now, there are few relevant published data about the prevalence of $\mathrm{CD}$ in the 
Moroccan general population and also in common clinical conditions usually associated with $\mathrm{CD}$ such as diabetes or autoimmune thyroiditis (AIT) $[4,5]$.

Both diseases share some common genetic background, mainly HLA molecules. In fact, the HLA-DQ2 genotype is found in $90 \%$ of celiac patients and in $55 \%$ of diabetics [6]. It was also reported that $33 \%$ of T1D patients who are homozygous for HLA-DQ2 are seropositive for anti-tTGA (tissue transglutaminase antibodies) versus $2 \%$ who are negative for HLA-DQ2/8 [7]. On the other hand, the role of gluten $[8]$ and viral infections $[9,10]$ in the etiopathogenesis of T1D is still a matter of controversy. Viral infections were also investigated in CD [11].

The presence of CD characterizes a subgroup of T1D patients that displays potential high risks of hypoglycemia $[12,13]$, microvascular complications $[14,15]$, and overall mortality [16]. Therefore, most of the guidelines recommend a systematic screening for CD in TID [17-19].

The main objective of the study was to determine the prevalence of specific auto-antibodies to CD in T1D in a Moroccan adult and pediatric population and to describe the clinical and biological characteristics of seropositive diabetic patients.

\section{Patients and Methods}

2.1. Study Design. A multicenter cross-sectional study was conducted in 276 adult and pediatric diabetic patients who were enrolled from five centers, including 2 pediatric centers, 2 adult endocrinology centers, and 1 specialized primary health care center. Patients were randomly recruited over a period of 23 months.

The sample size of the study was calculated with an estimated precision of the prevalence equal to $3 \%$ with a confidence interval of $95 \%$.

All patients were interviewed by the same investigator using a hetero-administered questionnaire focusing on most relevant symptoms of CD such as abdominal pain, bloating, diarrhea, constipation, vomiting, chronic fatigue, anorexia, and pallor, history of bone fractures and recent weight loss, ketoacidosis episodes, and hypoglycemic events that had occurred over a period of 6 months before the enrollment.

Patients' blood samples were collected and stored at $-20^{\circ} \mathrm{C}$ for subsequent serial testing.

The samples were tested for 4 relevant associated T1D auto-antibodies, including anti-GAD65-Ab (Aeskulisa ${ }^{\mathrm{TM}}$ GAD65, GmbH, threshold: $30 \mathrm{IU} / \mathrm{ml}$ ), anti-Insulin-Ab (Aeskulisa $^{\mathrm{TM}}$ Insulin, $\mathrm{GmbH}$, threshold: $18 \mathrm{IU} / \mathrm{ml}$ ), antiIA2-Ab (Aeskulisa ${ }^{\mathrm{TM}} \mathrm{IA} 2, \mathrm{GmbH}$, threshold: $30 \mathrm{IU} / \mathrm{ml}$ ), and anti-ZnT8-Ab (Aeskulisa ${ }^{\mathrm{TM}}$ anti-ZnT8, GmbH, threshold: $15 \mathrm{IU} / \mathrm{ml})$.

According to ESPGHAN guidelines for the diagnosis of CD [17], patients underwent an immunologic testing initially based on IgA anti-tTGA screening combined with IgA subclass quantification. Only positive IgA-tTGA cases were investigated for IgA anti-endomysial antibodies (EMA), and those who displayed low IgA-tTGA titers $(<10$ times the cutoff value) were proposed for HLA DQ2/DQ8 typing. The IgA deficiency cases underwent IgG anti-tTGA testing.

\subsection{Laboratory Testing Methods}

(i) Anti-tTG IgA and IgG testing was performed using commercial ELISA kits (tTG ELISA Orgentec, Diagnostika $\mathrm{GmbH}$, threshold: $10 \mathrm{IU} / \mathrm{ml}$ ).

(ii) EMA testing was done by an indirect immunofluorescence assay (Euroimmun AG, Lübeck, threshold: $1: 10$ ), with a semiquantitative assessment.

(iii) IgA class dosage was evaluated using a nephelometry system (BN Prospec, Siemens).

(iv) HLA DQ2 and DQ8 typing were performed on the basis of PCR-SSP (polymerase chain reaction-sequence specific primers) technique (One Lambda, USA) realized on DNA extracted from patient samples. Positive tTGA and EMA testings or irresolute cases following the serology and HLA typing were recommended for intestinal biopsy to confirm or to rule out the diagnosis of CD.

2.3. Statistical Analysis. The data were recorded and then analyzed using SPSS 16.0 statistical software. Descriptive statistics (mean, standard deviations, median, range, and proportions) were used to represent the trend and distribution of the results. The comparison between the 2 subgroups (celiac and diabetics vs. diabetics) was made using the independent $T$ test and the Mann-Whitney $U$ test for continuous outcomes and by chi-squared test and Fisher's exact test for proportions. Results were considered statistically significant when $p$ value is less than 0.05 .

2.4. Ethical Considerations. According to the Declaration of Helsinki (1964), patients have been informed about the objectives of the study. An informed consent was obtained from patients or their tutors if minors, prior to enrollment.

\section{Results}

The mean age of patients was $14.1 \pm 8$ years, ranging from 1 to 42 years, with 144 females versus 132 males (sex-ratio M/ $\mathrm{F}=0.91$ ). The mean duration of diabetes was $5.4 \pm 5.3$ years.

The overall seroprevalence of CD markers was $9.1 \%$ (IC $=95 \%$ ) including 24 positive cases of IgA-tTGA and 1 positive case of IgG-tTGA that displayed an IgA deficiency (seronegative for IgA-tTGA). Among all positive cases, 17 of them had high titers of tTG antibodies $(>100 \mathrm{IU} / \mathrm{ml})$ and 8 others had titers ranging between 13.23 and $68 \mathrm{IU} / \mathrm{ml}$. All the 24 positive cases on IgA-tTGA were also positive on EMA testing. The other one had IgA deficiency and had not been tested for IgA-EMA.

Among 8 cases of low IgA-tTGA titers, 4 were positive for HLADQ2, 1 was positive for HLADQ8, and 1 was positive for both HLADQ2 and DQ8. The two other cases, including the IgA deficiency case, had undergone an intestinal biopsy, confirming CD and went on GFD (Table 1).

The mean age of the pediatric population was $9 \pm 3.7$ years, of which, 17 were seropositive for CD specific markers. In contrast, the adult population had a mean age of 
TABle 1: The immunological profile of seropositive celiac patients.

\begin{tabular}{|c|c|c|c|c|c|c|}
\hline Patients & Age (yrs) & Anti-tTG IgA (IU/ml) & Anti-EMA IgA intensity & Anti-tTG IgG (IU/ml) & IgA dosage & HLA DQ2/8 typing \\
\hline Patient 01 & 2 & 68 & ++ & - & NL & DQ8 \\
\hline Patient 02 & 2 & $>200$ & ++++ & - & NL & - \\
\hline Patient 03 & 3 & 31 & ++ & - & NL & DQ2 \\
\hline Patient 04 & 7 & $>200$ & +++ & - & NL & - \\
\hline Patient 05 & 7 & $>200$ & ++++ & - & NL & - \\
\hline Patient 06 & 8 & 130 & +++ & - & NL & - \\
\hline Patient 07 & 9 & $>200$ & ++++ & - & NL & - \\
\hline Patient 08 & 10 & $>200$ & ++++ & - & NL & - \\
\hline Patient 09 & 10 & $>200$ & +++++ & - & NL & - \\
\hline Patient 10 & 10 & $>200$ & ++++ & - & NL & - \\
\hline Patient 11 & 10 & $>200$ & ++++ & - & NL & - \\
\hline Patient 12 & 11 & $>200$ & ++++ & - & NL & - \\
\hline Patient $13^{*}$ & 11 & 37 & + & - & NL & - \\
\hline Patient 14 & 12 & $>200$ & ++++ & - & NL & - \\
\hline Patient 15 & 13 & $>200$ & +++ & - & NL & - \\
\hline Patient 16 & 14 & 13.23 & + & - & NL & DQ2 \\
\hline Patient 17 & 14 & 112 & ++ & - & NL & - \\
\hline Patient 18 & 15 & 45 & + & - & NL & DQ2 \\
\hline Patient 19 & 15 & 58 & ++ & - & NL & DQ2 \\
\hline Patient 20 & 15 & 45 & + & - & NL & DQ2/DQ8 \\
\hline Patient $21^{*}$ & 16 & NG & - & 85 & $<0.26 \mathrm{~g} / \mathrm{L}$ & - \\
\hline Patient 22 & 18 & 125 & ++++ & - & NL & - \\
\hline Patient 23 & 23 & $>200$ & ++++ & - & NL & - \\
\hline Patient 24 & 33 & $>200$ & ++++ & - & NL & - \\
\hline Patient 25 & 35 & $>200$ & ++++ & - & NL & - \\
\hline
\end{tabular}

* Patient was confirmed $\mathrm{CD}$ with small bowel biopsy; $\mathrm{NG}=$ negative; $\mathrm{NL}=$ normal.

$21 \pm 6$ years, and 8 of them were seropositive as well. The other demographic, clinical, and biological characteristics of the two populations are shown in Table 2.

Among the associated T1D-tested auto-antibodies, $79.7 \%$ of cases had at least one positive auto-Ab, $42.4 \%$ had positive anti-GAD65 Ab, 36.2\% had positive anti-ZnT8 Ab, $31.9 \%$ had positive anti-Insulin $\mathrm{Ab}$, and $28 \%$ had anti-IA2 $\mathrm{Ab}$. The frequency of auto-Ab categories is given in Tables 3 and 4 , according to the population groups and CD-specific auto-Ab status, respectively.

According to the age at the onset of diabetes, the autoimmunity status of our patients (positive versus negative) was as follows: $63.2 \%$ vs. $67.9 \%, 29.5 \%$ vs. $21.4 \%, 6.4 \%$ vs. $10.7 \%$, and $0.9 \%$ vs. $0 \%$ in less than 10 years, between 10 and 20 years, between 20 and 30 years, and superior to 30 years, respectively.

Clinically, we observed a significant statistical difference between seropositive and seronegative cases concerning pallor (32\% vs. 9.2\%; $p=0.003)$, chronic constipation ( $56 \%$ vs. $27.5 \%$; $p=0.003$ ), abdominal pain (72\% vs. $37.8 \% ; p=0.001)$, bloating ( $64 \%$ vs. $30.7 \%$; $p=0.001)$, and recent weight loss $(68 \%$ vs. $45.4 \%$; $p=0.031)$. No statistically significant differences were noticed about diarrhea, chronic fatigue, loss of appetite, and vomiting (Table 4). Globally, CD seropositivity was significantly associated with a higher proportion of other autoimmune diseases ( $16 \%$ vs. $2.4 \%, p=0.008)$. In the seropositive group, we noticed 1 case of autoimmune thyroiditis, 1 case of Addison's disease, 1 case of lupus, and 1 case of idiopathic juvenile arthritis, versus 3 cases of autoimmune thyroiditis, 2 cases of Biermer anemia, and 1 case of Addison's disease in the seronegative group.
Seropositive patients had a higher median of HbAlc (11.30 (7.31_ 16.00) vs $\left.9.30\left(4.40 \_17.31\right) ; p=0.022\right)$ and a lower $Z$ score of height $(-0.90(-3.93$ _ 0.95$)$ vs -0.51 $(-4.54-2.18) ; p=0.029)$.

We observed that seropositive patients displayed a tendency towards a higher percentage of history of bone fractures (20\% vs. $8.8 \%, p=0.081)$, a higher mean insulin dosage (0.91 UI/Kg \pm 0.34 vs. $0.80 \mathrm{UI} / \mathrm{Kg} \pm 0.27 ; p=0.064)$, a higher female percentage ( $68 \%$ vs. $50.6 \% ; p=0.097)$, and a higher frequency of bad glycemic control (78.3\% vs. $57.8 \%$, $p=0.056$ ).

No significant differences were observed between the seropositive and seronegative groups regarding the mean age (12.95 years \pm 8 vs. 14.2 years $\pm 8 ; p=0.763)$, the mean diabetes duration ( 6.8 years \pm 7.5 vs. 5.2 years $\pm 5.1 ; p=0.295$ ), and the mean age at diabetes onset (6.8 years \pm 4.7 vs. 8.9 years $\pm 6.4 ; p=0.113$ ). There was no significant difference in relation to the overall percentage of familial cases of autoimmune diseases ( $40 \%$ vs. $38.2 \%, p=0.864$ ), the consanguinity rate $(24 \%$ vs. $20 \% ; p=0.636)$, the median Z-scores of both weight $(-0.50(-3.35 \ldots 1.48)$ vs. -0.33 $(-3.83-3.00) ; p=0.216)$, and body mass index (BMI) $\left(-0.07\left(-2.50 \_1.24\right)\right.$ vs. $\left.-0.04\left(-4.87 \_3.43\right) ; p=0.880\right)$ and the frequency of ketoacidosis at the onset of T1D $(66.7 \%$ vs. $60.9 \%, p=0.58$ ) or hypoglycemic events between the two groups.

\section{Discussion}

Our results display a relatively high prevalence of CDspecific auto-antibodies in Moroccan T1D patients. Actually, 


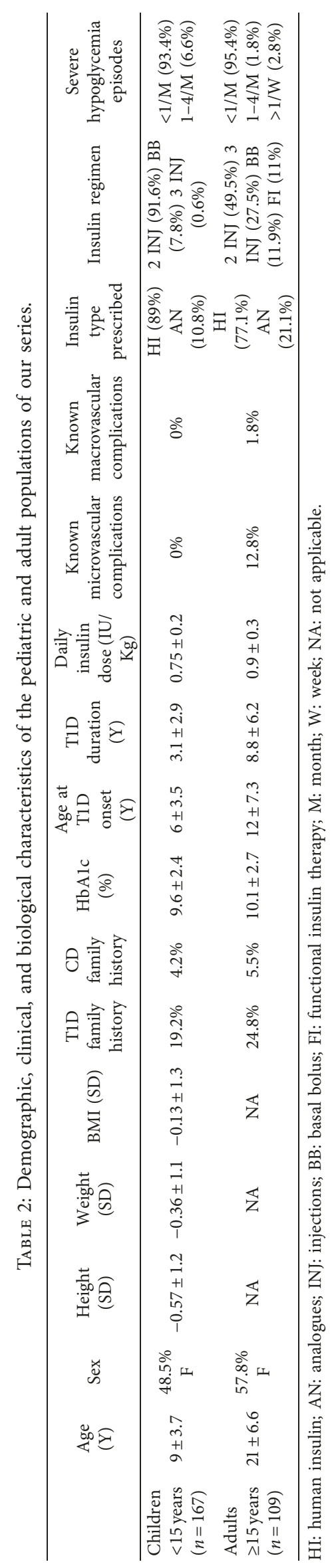


TABLE 3: The frequency of associated T1D auto-antibodies in the pediatric and adult populations of our series.

\begin{tabular}{lcccccc}
\hline & $\begin{array}{c}\text { Overall positivity of T1D } \\
\text { markers, } \\
n(\%)\end{array}$ & $\begin{array}{c}\text { GAD65-Ab, } \\
n(\%)\end{array}$ & $\begin{array}{c}\text { Anti-insulin Ab } \\
n(\%)\end{array}$ & $\begin{array}{c}\text { IA2-Abs } \\
n(\%)\end{array}$ & $\begin{array}{c}\text { ZnT8-Ab } \\
n(\%)\end{array}$ & $\begin{array}{c}\text { Positivity of specific CD } \\
\text { Abs } n(\%)\end{array}$ \\
\hline $\begin{array}{l}\text { Children }<15 \mathrm{y}(n=167) \\
\text { Adults } \geq 15 \mathrm{y}(n=109)\end{array}$ & $(145) 86.8 \%$ & $(77) 46.1 \%$ & $(51) 30.5 \%$ & $(61) 36.5 \%$ & $(69) 41.3 \%$ & $(17) 10.2 \%$ \\
\hline
\end{tabular}

TABle 4: Comparison of clinical and biological profiles between seropositive and seronegative patients.

\begin{tabular}{|c|c|c|c|}
\hline & Seropositive group, $n(\%)$ & Seronegative group, $n(\%)$ & $p$ value \\
\hline \multicolumn{4}{|l|}{ Clinical manifestations } \\
\hline Pallor & $8(32 \%)$ & $23(9.2 \%)$ & $0.003^{*}$ \\
\hline Chronic constipation & $14(56 \%)$ & $69(27.5 \%)$ & $0.003^{*}$ \\
\hline Abdominal pain & $18(72 \%)$ & $94(37.8 \%)$ & $0.001^{*}$ \\
\hline Bloating & $16(64 \%)$ & $77(30.7 \%)$ & $0.001^{*}$ \\
\hline Recent weight loss & $17(68 \%)$ & $114(45.4 \%)$ & $0.031^{*}$ \\
\hline Diarrhea & $9(36 \%)$ & $54(21.9 \%)$ & 0.111 \\
\hline Nausea and vomiting & $4(16 \%)$ & $31(12.7 \%)$ & 0.416 \\
\hline Chronic fatigue & $13(52 \%)$ & $92(36.7 \%)$ & 0.132 \\
\hline Lack of appetite & $9(36 \%)$ & $70(27.9 \%)$ & 0.392 \\
\hline Other associated AIDs & $4(16 \%)$ & $6(2.4 \%)$ & $0.008^{*}$ \\
\hline Median $Z$ scores of height & $-0.90(-3.93-0.95)$ & $-0.51(-4.54-2.18)$ & $0.029^{*}$ \\
\hline Median $Z$ scores of BMI & $-0.07(-2.50-1.24)$ & $-0.04(-4.87-3.43)$ & 0.880 \\
\hline Median HbA1c & $11.30\left(7.31 \_16.00\right)$ & $9.30\left(4.40_{-} 17.31\right)$ & $0.022^{*}$ \\
\hline \multicolumn{4}{|l|}{ T1D-tested auto-antibodies } \\
\hline GAD65-ab (\%) & (13) $52 \%$ & (104) 41.4\% & 0.308 \\
\hline GAD65-ab mean titers (UI/ml) & $231.1(33.15-500)$ & $184.2(30.02-500)$ & 0.096 \\
\hline Anti-insulin-ab (\%) & (7) $28 \%$ & (81) $32.3 \%$ & 0.662 \\
\hline Anti-insulin-ab mean titers (UI/ml) & $83.49(18.04-300)$ & $47.99(18.24-300)$ & 0.603 \\
\hline IA2-ab (\%) & (11) $44 \%$ & (67) $26.7 \%$ & 0.067 \\
\hline IA2-ab mean titers $(\mathrm{UI} / \mathrm{ml})$ & $109.8(30.85-370.5)$ & $176.54(30.29-500)$ & 0.064 \\
\hline ZnT8-ab (\%) & (11) $44 \%$ & (89) $35.5 \%$ & 0.397 \\
\hline ZnT8-ab mean titers (UI/ml) & $170.77(16-47-500)$ & $194.43(15.10-500)$ & $0.002^{*}$ \\
\hline Overall positivity (\%) & (23) $92 \%$ & (197) $78.5 \%$ & 0.109 \\
\hline
\end{tabular}

AID: autoimmune diseases; BMI: body mass index. *Statistically significant differences.

a similar Moroccan study has shown a higher rate of tTGA positivity (13\%), but regarding the very small sample of adult T1D patients studied (31 cases), these data seem to overestimate the real prevalence of associated auto-antibodies to CD [4]. In contrary and in a similar context, Azzi et al. [5] reviewed the records of $720 \mathrm{~T} 1 \mathrm{D}$ pediatric patients and concluded a biopsy-proven CD prevalence of $3.05 \%$. However, the authors have considered this rate to be a definite underestimation since most of patients were not systematically screened for CD. On the other hand, the prevalence rate found in our study is comparable to that reported by Barerra et al. (9.9\%), Salardi et al. (8.8\%), Larsson et al. (9\%), Gabriel et al. (9.2\%), Gillet et al. (8.2\%), and Mankaï et al. (8.3\%) [20-25]. However, it is much higher than that reported by Mont-Serrat et al. $(2.5 \%)$ [26] and lower than the findings of Boudraa et al. (16.4\%), Al-Hussaini et al. (20\%), and Ashabani et al. $(21.3 \%)$ [27-29]. In fact, the reasons behind the variability of the prevalence rate of $\mathrm{CD}$ in $\mathrm{T} 1 \mathrm{D}$ patients between different countries (Table 5) remain mostly unexplained [3]. On the other side, the potential impact of sex and age on the frequency of CD was assessed by Cerutti et al. and concluded in a large cohort of $4322 \mathrm{~T} 1 \mathrm{D}$ and CD patients that female sex is an independent predictive risk factor for developing CD [33]. Similar findings have also been reported by many other authors [27, 34-38]. However, Pham-short et al. did not find such associations in their large meta-analysis gathering 26 studies [39].

Our study did not display a significant difference in the mean age between the 2 groups of patients as many similar studies did [27, 31, 34, 40, 41]. However, Cerutti et al. reported that the onset of diabetes before 4 years of age is an independent risk factor for developing CD (OR: 3.27 95\% IC 2.20-4.85) [33]. Such observation is also supported by many other authors [25, 31, 34, 36, 40, 42]. The results concerning the duration of diabetes remain, however, more controversial probably due to differences in CD screening strategies as well as the design of the studies.

We observed significant differences regarding the following clinical findings: pallor, chronic constipation, abdominal pain, bloating, and recent weight loss. These findings are comparable to those of the study of Hansen et al. [31] that displayed significant differences between $33 \mathrm{CD}$ T1D patients compared to 236 T1D only, concerning abdominal pain, loose and/or frequent stool, bloating, constipation, arthralgia, tiredness, and frequent hypoglycemia, 
TABLE 5: Seroprevalence rate of CD in T1D according to different series.

\begin{tabular}{|c|c|c|c|c|}
\hline Author & Country & Sample size & Mean age & Seroprevalence rate \\
\hline \multicolumn{5}{|l|}{ Europe } \\
\hline Crone et al. [30] & Austria & 157 & $14.8(4-21)$ & $13.5 \%$ \\
\hline Hansen et al. [31] & Denmark & 269 & $10.9(1.5-16)$ & $12.1 \%$ \\
\hline Barerra et al. [20] & Italy & 273 & - & $9.9 \%$ \\
\hline Salardi et al. [21] & Italy & 331 & $8.1 \pm 4.3$ & $8.8 \%$ \\
\hline Larsson et al. [22] & Sweden & 300 & - & $9.0 \%$ \\
\hline \multicolumn{5}{|l|}{ North America } \\
\hline Aktay et al. [32] & USA & 218 & $13.7(4-21)$ & $7.7 \%$ \\
\hline Gillet et al. [24] & Canada & 233 & $12.9(1.3-19.2)$ & $8.2 \%$ \\
\hline \multicolumn{5}{|c|}{ Middle east and north Africa } \\
\hline Bouderra et al. [29] & Algeria & 116 & $(1-19.5)$ & $16.4 \%$ \\
\hline Al-Hussaini et al. [27] & Saudi Arabia & 106 & $8.5(1-15.5)$ & $20 \%$ \\
\hline Ashabani et al. [28] & Libya & 234 & $12.8(2-50)$ & $21.3 \%$ \\
\hline Mankai et al. [25] & Tunisia & 205 & $11(1-11)$ & $2.5 \%$ \\
\hline Our study & Morocco & 276 & $14.1(1-42)$ & $9.1 \%$ \\
\hline
\end{tabular}

whereas no difference was reported about other symptoms like aphthous ulcers and tooth enamel defects.

On another side, the impact of CD on growth in diabetic patients as well as the potential benefit of the gluten-free diet (GFD) on this parameter is still controversial. About that, Hansen et al. [31] found that at the time of CD diagnosis, CD-T1D patients had a smaller mean weight SD than T1D patients. Other authors reported similar results for weight SD $[27,30,34,43]$ and height SD [20, 30, 34, 43]. Our study showed a significant difference between the two groups in only height SD.

It is known that $\mathrm{CD}$ is generally associated with an increased risk of having other autoimmune diseases (AID). By the way, Not et al. [44] reported a strong association of CD with the presence of other AID in T1D patients $(37.5 \%$ vs. $6.3 \%, p<0.0001)$. The most frequent AID in such a population is AIT $[31,33]$. The overall percentage of AID among seropositive patients in our series is high and statistically significant (16\%) but might be underestimated, because there was no systematic screening for AID in both diabetic and celiac patients. Actually, the seroconversion of CD happens in the first years of the T1D onset and almost $85 \%$ are diagnosed by 5 years [45].

Furthermore, it is recommended to screen for CD in T1D patients who particularly manifest unexplained bad glycemic control [46]. This recommendation is based on the study of Leeds et al. [13] who observed that CD-T1D patients have a higher $\mathrm{HbA} 1 \mathrm{c}$ level in comparison with T1D adult patients $(8.2 \%$ vs. $7.5 \%, p=0.05)$. Similarly, our study confirms these findings and shows a significantly elevated median of HbA1c level in seropositive cases, in contrary to several series showing no significant difference [23, 27, 28, 31, 35, 47-49].

On the basis of the potential impact of CD on insulin requirements, some authors recommend a screening for $\mathrm{CD}$ in patients with unusual low doses of insulin. In fact, this may be explained essentially by malabsorption. Linked to that, a case-control study conducted by Mohn et al. noticed the reduction of insulin doses 12 months prior to $\mathrm{CD}$ diagnosis (0.6 UI/Kg vs. $0.9 \mathrm{UI} / \mathrm{Kg}, p=0.05)$. The same observation was reported by Abid et al. and Poulain et al. [36, 50]. The authors reported a rise in insulin requirements after the startup of a GFD $[12,51]$. Regarding our cases, we observed a tendency towards higher insulin doses in seropositive patients, which may reflect the differences in glycemic control for this group of patients.

T1D is associated with a 2- to 4-fold increase of fractures' global risk [52]. To the same extent, Heikkilä et al. has found in their meta-analysis that CD is associated with an increase in the global risk of fractures with an OR of 1.30 [53]. Furthermore, Lunt et al. demonstrated that BMD (bone mineral density) evaluated by DXA (dual-energy X-ray absorptiometry) in the lumbar region of nontreated adult celiac and type 1 diabetic women is inferior in comparison with type 1 diabetics only [54]. In our patient series, we observed a higher proportion of positive bone fractures' history in T1D patients compared to seronegative diabetics ( $20 \%$ vs. $8.8 \%, p=0.081$ ). This observation requires further investigation especially in the adult population.

On another side, the influence of CD status on the course of T1D remains controversial, especially regarding degenerative complications [55]. However, a Swedish study pinpointed the fact that it is the duration of CD that conditions the impact of CD on diabetic retinopathy [15]. The authors reported a beneficial effect the first 5 years (HR 0.57 95\% CI: 0.36-0.91), no effect during the following 5 years (HR 1.03 95\% CI: 0.68-1.57) and an aggravation after 10 years (HR of 2.83 after 10 years). Otherwise, CD is associated with a higher risk of end-stage renal disease in T1D patients, with a HR of 2.03 after 10 years [55]. Leed et al. have reported similar results concerning diabetic nephropathy, with a positive effect of GFD on renal markers after 1 year [13].

The effect of CD status on the severity of T1D onset has been studied by Rami et al. [49] and did not report any association. Our study came to the same conclusions. However, a clinical form of CD occurring before T1D has been reported in the literature, characterized by severe diabetes onset and a higher prevalence of other AID [56]. Similarly, our only patient for whom the diagnosis of CD 
was made before T1D onset corresponded to a case of IgA deficiency associated with epilepsy, with Addison's disease and asthma. Moreover, CD does not seem to be associated with a higher risk of ketoacidosis and diabetic coma during the course of T1D [30, 49, 57, 58].

To the best of our knowledge, our study is the first relevant multicenter cross-sectional study conducted in Morocco. At the end, our results give evidence of a high CDspecific auto-antibodies positivity in T1D but remain relatively limited to well assess the impact of such associations on the course of T1D. In fact, the small number of seropositive patients and the necessity of a further intestinal biopsy as well as a follow-up are the factors to be considered in the conclusions to be drawn from these data. With the same perspectives in mind, we have communicated the findings of our $\mathrm{CD}$ laboratory testing to the physicians for further investigation (biopsy) and GFD if required, with an active surveillance.

\section{Conclusion}

The current study concluded a high prevalence of CDspecific antibodies in Moroccan T1D patients. In comparison with the diabetic group, seropositive celiac and diabetic patients displayed significant association with poor glycemic control, lower height SD, and an increased frequency of other AIDs.

These findings emphasize the benefit of a systematic screening for $\mathrm{CD}$ in diabetic patients, which can hopefully minimize the potential risk of complications due to undiagnosed CD. Furthermore, controlled longitudinal studies in a larger sample with an assessment of the potential benefit of a GFD, especially in asymptomatic patients, are needed.

\section{Data Availability}

The data used to support the findings of this study are available from the corresponding author upon request.

\section{Conflicts of Interest}

The authors declare that there are no conflicts of interest.

\section{Acknowledgments}

The authors wish to thank all the participants for their contribution to this study. This study was financially supported by the University Hospital of Marrakech.

\section{References}

[1] J. A. Walker-Smith and W. Grigor, "Coliac disease in a diabetic child," The Lancet, vol. 293, no. 7603, p. 1021, 1969.

[2] A. Szaflarska-Popławska, "Coexistence of coeliac disease and type 1 diabetes," Przeglad Gastroenterologiczny, vol. 9, no. 1, pp. 11-17, 2013.

[3] P. Elfström, J. Sundström, and J. F. Ludvigsson, "Systematic review with meta-analysis: associations between coeliac disease and type 1 diabetes," Alimentary Pharmacology \& Therapeutics, vol. 40, no. 10, pp. 1123-1132, 2014.
[4] A. D. Bourhanbour, S. Ouadghiri, N. Benseffaj, and M. Essakalli, "Dépistage sérologique de la maladie coeliaque chez des patients marocains atteints de diabète type 1," Pan African Medical Journal, vol. 24, no. 1, p. 103, 2016.

[5] K. H. Azzi, S. Maniar, Z. Imane, M. H. Gharbi, A. Chraibi, and A. Balafrej, "Association diabète de type 1 et maladie coeliaque. A propos de 22 cas marocains," Médecine du Maghreb, vol. 184, pp. 28-32, 2011.

[6] R. Hermann, H. Turpeinen, A. P. Laine et al., "HLA DR-DQencoded genetic determinants of childhood-onset type 1 diabetes in Finland: an analysis of 622 nuclear families," Tissue Antigens, vol. 62, no. 2, pp. 162-169, 2003.

[7] L. M. Sollid and B. Jabri, "Is celiac disease an autoimmune disorder?," Current Opinion in Immunology, vol. 17, no. 6, pp. 595-600, 2005.

[8] J. C. Antvorskov, K. Josefsen, K. Engkilde, D. P. Funda, and K. Buschard, "Dietary gluten and the development of type 1 diabetes," Diabetologia, vol. 57, no. 9, pp. 1770-1780, 2014.

[9] K. T. Coppieters, A. Wiberg, S. M. Tracy, and M. G. von Herrath, "Immunology in the clinic review series: focus on type 1 diabetes and viruses: the role of viruses in type 1 diabetes: a difficult dilemma," Clinical \& Experimental Immunology, vol. 168, no. 1, pp. 5-11, 2012.

[10] L. C. Stene and M. Rewers, "Immunology in the clinic review series; focus on type 1 diabetes and viruses: the enterovirus link to type 1 diabetes: critical review of human studies," Clinical \& Experimental Immunology, vol. 168, no. 1, pp. 12-23, 2012.

[11] L. C. Stene, M. C. Honeyman, E. J. Hoffenberg et al., "Rotavirus infection frequency and risk of celiac disease autoimmunity in early childhood: a longitudinal study," The American Journal of Gastroenterology, vol. 101, no. 10, pp. 2333-2340, 2006.

[12] D. Iafusco, F. Rea, and F. Prisco, "Hypoglycemia and reduction of the insulin requirement as a sign of celiac disease in children with IDDM," Diabetes Care, vol. 21, no. 8, pp. 1379-1380, 1998.

[13] J. S. Leeds, A. D. Hopper, M. Hadjivassiliou, S. Tesfaye, and D. S. Sanders, "High prevalence of microvascular complications in adults with type 1 diabetes and newly diagnosed celiac disease," Diabetes Care, vol. 34, no. 10, pp. 2158-2163, 2011.

[14] K. Mollazadegan, M. Fored, S. Lundberg et al., "Risk of renal disease in patients with both type 1 diabetes and coeliac disease," Diabetologia, vol. 57, no. 7, pp. 1339-1345, 2014.

[15] K. Mollazadegan, M. Kugelberg, S. M. Montgomery, D. S. Sanders, J. Ludvigsson, and J. F. Ludvigsson, "A population-based study of the risk of diabetic retinopathy in patients with type 1 diabetes and celiac disease," Diabetes Care, vol. 36, no. 2, pp. 316-321, 2013.

[16] K. Mollazadegan, D. S. Sanders, J. Ludvigsson, and J. F. Ludvigsson, "Long-term coeliac disease influences risk of death in patients with type 1 diabetes," Journal of Internal Medicine, vol. 274, no. 3, pp. 273-280, 2013.

[17] S. Husby, S. Koletzko, I. R. Korponay-Szabó et al., "European society for pediatric gastroenterology, hepatology, and nutrition guidelines for the diagnosis of coeliac disease," Journal of Pediatric Gastroenterology and Nutrition, vol. 54, no. 1, pp. 136-160, 2012.

[18] IDF I, Global IDF/ISPAD Guideline for Diabetes in Childhood and Adolescence, 2011, https://www.ispad.org/ sites/default/files/resources/files/idf-ispad_diabetes_in_childhood_ and_adolescence_guidelines_2011_0.pdf.

[19] J. C. Bai, M. Fried, G. R. Corazza et al., "World gastroenterology organisation global guidelines on celiac disease," 
Journal of Clinical Gastroenterology, vol. 47, no. 2, pp. 121126, 2013.

[20] G. Barera, R. Bonfanti, M. Viscardi et al., "Occurrence of celiac disease after onset of type 1 diabetes: a 6-year prospective longitudinal study," Pediatrics, vol. 109, no. 5, pp. 833-838, 2002.

[21] S. Salardi, U. Volta, S. Zucchini et al., "Prevalence of celiac disease in children with type 1 diabetes mellitus increased in the mid-1990s: an 18-year longitudinal study based on antiendomysial antibodies," Journal of Pediatric Gastroenterology and Nutrition, vol. 46, no. 5, pp. 612-614, 2008.

[22] K. Larsson, A. Carlsson, E. Cederwall et al., "Annual screening detects celiac disease in children with type 1 diabetes," $P e$ diatric Diabetes, vol. 9, no. 4, pp. 354-359, 2008.

[23] S. Gabriel, I. Mihaela, B. Angela, A. Mariana, and D. Doru, "Prevalence of IgA antitissue transglutaminase antibodies in children with type 1 diabetes mellitus," Journal of Clinical Laboratory Analysis, vol. 25, no. 3, pp. 156-161, 2011.

[24] P. M. Gillett, H. M. Gillett, D. M. Israel et al., "High prevalence of celiac disease in patients with type 1 diabetes detected by antibodies to endomysium and tissue transglutaminase," Canadian Journal of Gastroenterology, vol. 15, no. 5, pp. 297-301, 2001.

[25] A. Mankaï, H. Ben Hamouda, F. Amri et al., "Screening by anti-endomysium antibodies for celiac disease in Tunisian children with type 1 diabetes mellitus," Gastroentérologie Clinique et Biologique, vol. 31, no. 5, pp. 462-466, 2007.

[26] C. Mont-Serrat, C. Hoineff, R. M. R. Meirelles, and R. Kupfer, "Diabetes e doenças auto-imunes: prevalência de doença celíaca em crianças e adolescentes portadores de diabetes melito tipo 1," Arquivos Brasileiros de Endocrinologia \& Metabologia, vol. 52, no. 9, pp. 1461-1465, 2008.

[27] A. Al-Hussaini, N. Sulaiman, M. Al-Zahrani, A. Alenizi, and I. El Haj, "High prevalence of celiac disease among Saudi children with type 1 diabetes: a prospective cross-sectional study," BMC Gastroenterology, vol. 12, no. 1, p. 180, 2012.

[28] A. Ashabani, U. Abushofa, S. Abusrewill, M. Abdelazez, L. Tučková, and H. Tlaskalová-Hogenová, "The prevalence of coeliac disease in Libyan children with type 1 diabetes mellitus," Diabetes/Metabolism Research and Reviews, vol. 19, no. 1, pp. 69-75, 2003.

[29] G. Boudraa, W. Hachelaf, M. Benbouabdellah, M. Belkadi, F. Z. Benmansour, and M. Touhami, "Prevalence of coeliac disease in diabetic children and their first-degree relatives in West Algeria: screening with serological markers," Acta Paediatrica, vol. 85, no. 412, pp. 58-60, 1996.

[30] J. Crone, B. Rami, W. D. Huber, G. Granditsch, and E. Schober, "Prevalence of celiac disease and follow-up of EMA in children and adolescents with type 1 diabetes mellitus," Journal of Pediatric Gastroenterology and Nutrition, vol. 37, no. 1, pp. 67-71, 2003.

[31] D. Hansen, B. Brock-Jacobsen, E. Lund et al., "Clinical benefit of a gluten-free diet in type 1 diabetic children with screeningdetected celiac disease: a population-based screening study with 2 years' follow-up," Diabetes Care, vol. 29, no. 11, pp. 2452-2456, 2006.

[32] A. N. Aktay, P. C. Lee, V. Kumar, E. Parton, D. T. Wyatt, and S. L. Werlin, "The prevalence and clinical characteristics of celiac disease in juvenile diabetes in Wisconsin," Journal of Pediatric Gastroenterology and Nutrition, vol. 33, no. 4, pp. 462-465, 2001.

[33] F. Cerutti, G. Bruno, F. Chiarelli, R. Lorini, F. Meschi, and C. Sacchetti, "Younger age at onset and sex predict celiac disease in children and adolescents with type 1 diabetes: an
Italian multicenter study," Diabetes Care, vol. 27, no. 6, pp. 1294-1298, 2004.

[34] E. E. Fröhlich-Reiterer, S. Kaspers, S. Hofer et al., "Anthropometry, metabolic control, and follow-up in children and adolescents with type 1 diabetes mellitus and biopsy-proven celiac disease," The Journal of Pediatrics, vol. 158, no. 4, pp. 589.e2-593.e2, 2011.

[35] K. Karavanaki, K. Kakleas, E. Paschali et al., "Screening for associated autoimmunity in children and adolescents with type 1 diabetes mellitus (T1DM)," Hormone Research in Paediatrics, vol. 71, no. 4, pp. 201-206, 2009.

[36] C. Poulain, C. Johanet, C. Delcroix, C. Lévy-Marchal, and N. Tubiana-Rufi, "Prevalence and clinical features of celiac disease in 950 children with type 1 diabetes in France," Diabetes \& Metabolism, vol. 33, no. 6, pp. 453-458, 2007.

[37] B. Shahbazkhani, T. Faezi, M. R. Akbari et al., "Coeliac disease in Iranian type I diabetic patients," Digestive and Liver Disease, vol. 36, no. 3, pp. 191-194, 2004.

[38] O. Uibo, K. Heilman, T. Rägo et al., "Symptomless celiac disease in type 1 diabetes: 12-year experience in Estonia," Pediatrics International, vol. 52, no. 2, pp. 230-233, 2010.

[39] A. Pham-Short, K. C. Donaghue, G. Ambler, H. Phelan, S. Twigg, and M. E. Craig, "Screening for celiac disease in type 1 diabetes: a systematic review," Pediatrics, vol. 136, no. 1 , pp. e170-e176, 2015.

[40] M. Aralica, J. Matica, I. Barbarić, S. Severinski, and S. Štifter, "Serological screening for celiac disease in Croatian children with type I diabetes mellitus," Clinical Biochemistry, vol. 44, no. 7, p. 521, 2011.

[41] Z. Djurić, H. Stamenković, T. Stanković et al., "Celiac disease prevalence in children and adolescents with type 1 diabetes from Serbia," Pediatrics International, vol. 52, no. 4, pp. 579-583, 2010.

[42] A. Pham-Short, K. C. Donaghue, G. Ambler, A. K. Chan, and M. E. Craig, "Coeliac disease in type 1 diabetes from 1990 to 2009: higher incidence in young children after longer diabetes duration," Diabetic Medicine, vol. 29, no. 9, pp. e286-e289, 2012.

[43] J. H. Simmons, G. J. Klingensmith, K. McFann et al., "Celiac autoimmunity in children with type 1 diabetes: a two-year follow-up," The Journal of Pediatrics, vol. 158, no. 2, pp. 276.e1-281.e1, 2011.

[44] T. Not, A. Tommasini, G. Tonini et al., "Undiagnosed coeliac disease and risk of autoimmune disorders in subjects with type I diabetes mellitus," Diabetologia, vol. 44, no. 2, pp. 151-155, 2001.

[45] T. Saukkonen, E. Savilahti, H. Reijonen et al., "Coeliac disease: frequent occurrence after clinical onset of insulin-dependent diabetes mellitus," Diabetic Medicine, vol. 13, no. 5, pp. 464-470, 1996.

[46] American Diabetes Association, "Standards of medical care in diabetes-2016: summary of revisions," Diabetes Care, vol. 39, no. 1, pp. S4-S5, 2016.

[47] A. Cohn, A. M. Sofia, and S. S. Kupfer, "Type 1 diabetes and celiac disease: clinical overlap and new insights into disease pathogenesis," Current Diabetes Reports, vol. 14, no. 8, p. 517, 2014.

[48] C. Goh and K. Banerjee, "Prevalence of coeliac disease in children and adolescents with type 1 diabetes mellitus in a clinic based population," Postgraduate Medical Journal, vol. 83, no. 976, pp. 132-136, 2007.

[49] B. Rami, Z. Sumnik, E. Schober et al., "Screening detected celiac disease in children with type 1 diabetes mellitus: effect on the clinical course (a case control study)," Journal of 
Pediatric Gastroenterology and Nutrition, vol. 41, no. 3, pp. 317-321, 2005.

[50] N. Abid, O. McGlone, C. Cardwell, W. McCallion, and D. Carson, "Clinical and metabolic effects of gluten free diet in children with type 1 diabetes and coeliac disease," Pediatric Diabetes, vol. 12, no. 4, pp. 322-325, 2011.

[51] A. Mohn, M. Cerruto, D. Iafusco et al., "Celiac disease in children and adolescents with type I diabetes: importance of hypoglycemia," Journal of Pediatric Gastroenterology and Nutrition, vol. 32, no. 1, pp. 37-40, 2001.

[52] V. N. Shah, C. S. Shah, and J. K. Snell-Bergeon, "Type 1 diabetes and risk of fracture: meta-analysis and review of the literature," Diabetic Medicine, vol. 32, no. 9, pp. 1134-1142, 2015.

[53] K. Heikkilä, J. Pearce, M. Mäki, and K. Kaukinen, "Celiac disease and bone fractures: a systematic review and metaanalysis," The Journal of Clinical Endocrinology \& Metabolism, vol. 100, no. 1, pp. 25-34, 2015.

[54] H. Lunt, C. M. Florkowski, H. B. Cook, and M. R. Whitehead, "Bone mineral density, type 1 diabetes, and celiac disease," Diabetes Care, vol. 24, no. 4, pp. 791-792, 2001.

[55] S. F. Bakker, M. E. Tushuizen, B. M. E. von Blomberg, H. J. Bontkes, C. J. Mulder, and S. Simsek, "Screening for coeliac disease in adult patients with type 1 diabetes mellitus: myths, facts and controversy," Diabetology \& Metabolic Syndrome, vol. 8, no. 1, p. 51, 2016.

[56] G. Valerio, L. Maiuri, R. Troncone et al., "Severe clinical onset of diabetes and increased prevalence of other autoimmune diseases in children with coeliac disease diagnosed before diabetes mellitus," Diabetologia, vol. 45, no. 12, pp. 1719-1722, 2002.

[57] M. Kurien, K. Mollazadegan, D. S. Sanders, and J. F. Ludvigsson, "A nationwide population-based study on the risk of coma, ketoacidosis and hypoglycemia in patients with celiac disease and type 1 diabetes," Acta Diabetologica, vol. 52, no. 6, pp. 1167-1174, 2015.

[58] I. Taler, M. Phillip, Y. Lebenthal, L. de Vries, R. Shamir, and S. Shalitin, "Growth and metabolic control in patients with type 1 diabetes and celiac disease: a longitudinal observational case-control study," Pediatric Diabetes, vol. 13, no. 8, pp. 597-606, 2012. 


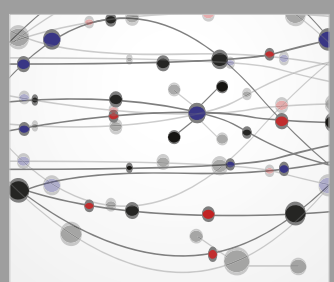

The Scientific World Journal
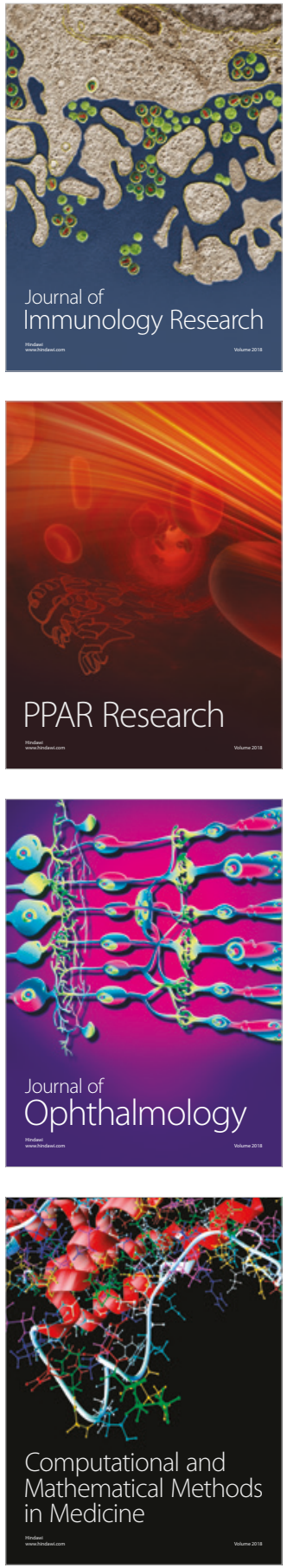

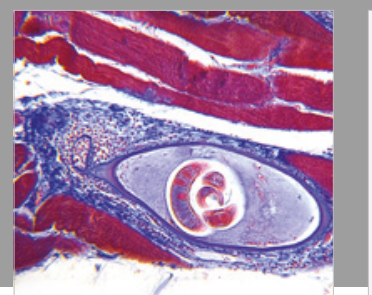

Gastroenterology Research and Practice

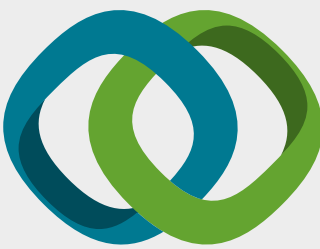

\section{Hindawi}

Submit your manuscripts at

www.hindawi.com
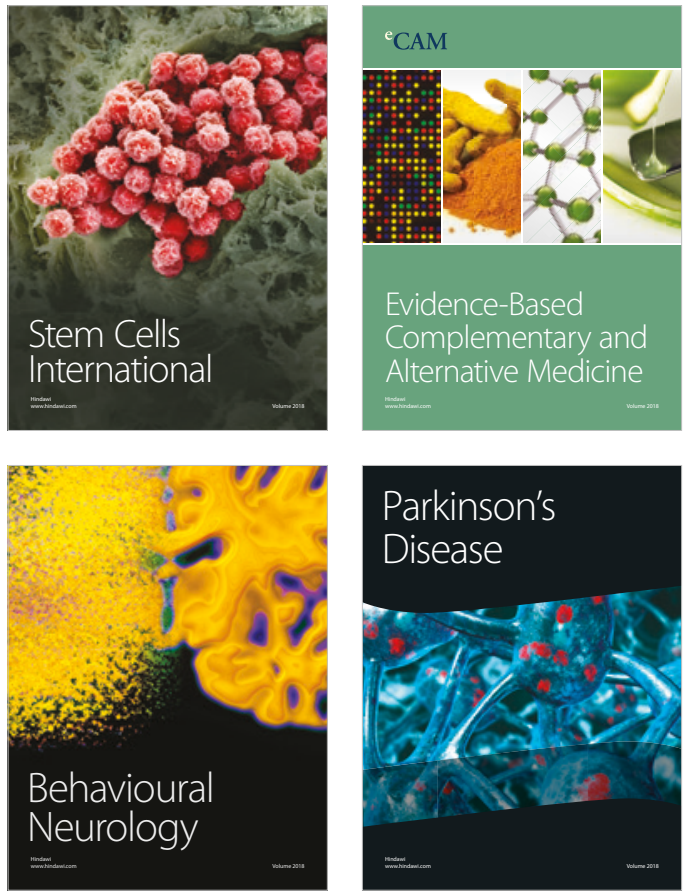

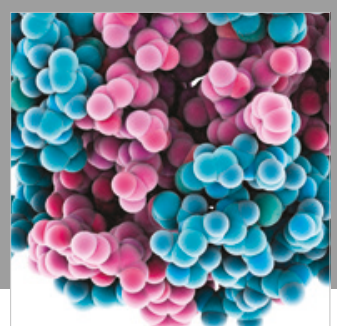

ournal of

Diabetes Research

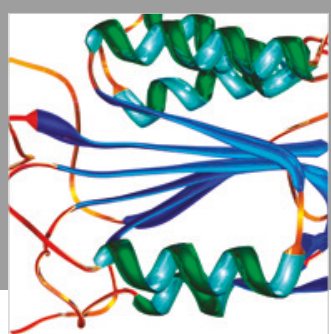

Disease Markers
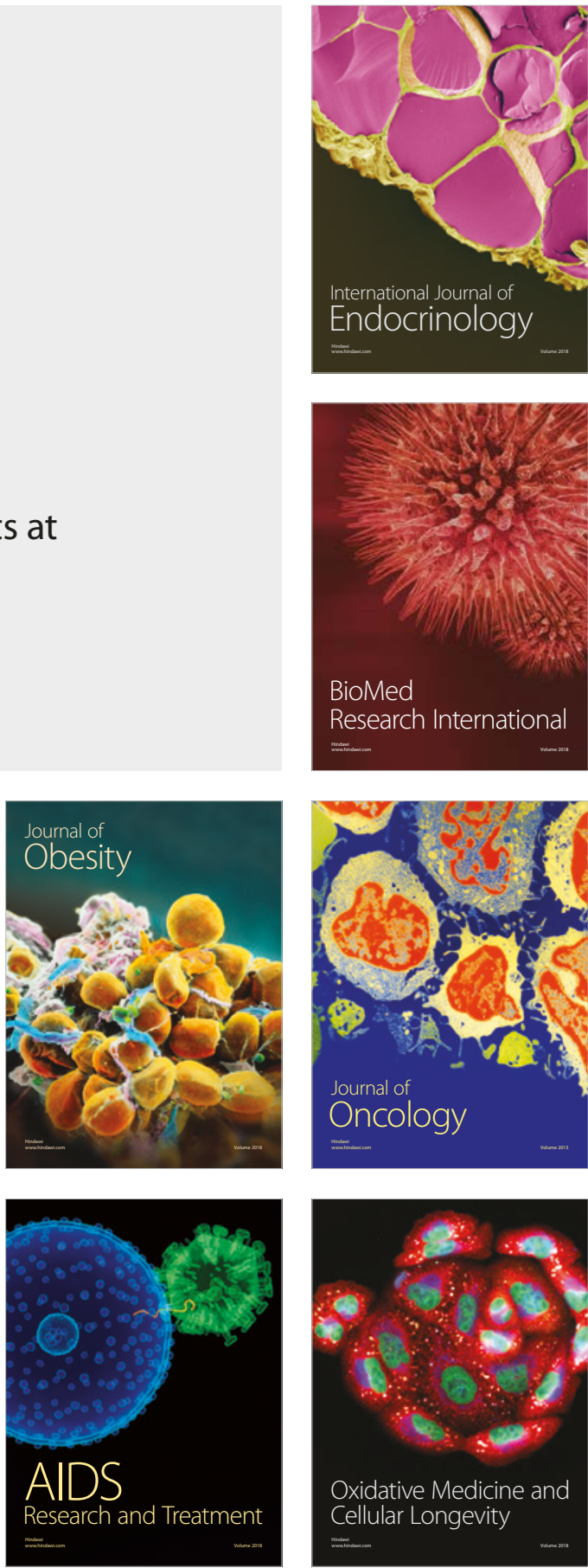